lees than can be obtained from the same class on any other system, and would do no injury whatever to other practisioners in the neighbourhood.

I now come to my last point, which, like a lady's postzcript, is perhaps that to which I wish to draw most attention. This is the question of direct private contract between ourselves as individuals and our patients of the middle and spper classes. The suggestion is, shortly, that our patients should pay by the year instead of by the attendance. Under the title of "health assurance" this proposal has been made before, but met with very little general acceptance, mainly on account of the entirely inadequate sums which were suggested for the annual payments. Before discussing these, let us in the spirit of Mr. Bryant's address consider the matter first from the point of view of the public, our patients. The advantages to them are: (1) that the most serious item of expense in an illness-viz., the medical bill-would be avoided; (2) the principle of mutual assurance would come into play, and those who were fortunate enough to escape much illness in any given year would help to pay for those who might be invalided; and (3) there would be no reas on for that delay in sending for the medical man which now too often occurs, and which frequently leads to such serious results; the direct benefit to the public health would thus be very great. Now let us see how we ourselves should be affected, and in order to do so we must consider the question of the annual retaining fee. The amonnt of this would naturally vary according to the patient's position, the number in family, and the general state of health of the household. The annual fee should bear a relation to the visiting fee charged under the present system, and, like the Fatter, it should be fairly uniform amongst the medical men practising in the same neighbourhood. I bave, for the purpose of ascertaining how this system would work out, taken from $m y$ ledger the amounts actually paid to me during the last four years (1889-1893) by twenty patients to whom I charge the same visiting fee-viz , $5 s$. These have not been selected as having had either large or small accounts, but have been taken just as they came. I find that during the four years these twenty patients have paid me almost exactly $£ 600$, or an average of $£ 150$ per annum. A man paying this visiting fee may easily in any year incur a doctor's bill of $£ 30$ or $£ 40$ or more; it is, therefore, not unreasonable to suppose that he would be willing to pay an annual retaining fee of $£ 10$ per annum, which would oover all ordinary sickness in his family and household. Now if these twenty patients had each paid me $£ 10$ per annum during the four years I should have received in the aggregate $£ 800$, or an average of $£ 200$ per annum, from them, being an increase of 25 per cent. on my actual receipts. I merely take this as an illustration. I do not say that 58 . per visit is correlative to $£ 10$ per annum; in many cases more would be necessary, in a few less. As I have said, the amount should be fixed in each case by personal arrangement and should bear a relation to the fee otherwise charged. It is clear that there is nothing in such an arrangement which would in any way impair the confidential relations which ought to exist between the medical man and the patient. The retaining fee would not, of course, include confinements, serious operations, night visits, or consultations, and would be terminable by three months' notice on either side. In addition to the actual increase of income which we might anticipate from the adoption of this system, we should derive 3. further great advantage from the regularity of our receipts. We should not, as at present, be dependent for an improvement in our incomes on the chances of an epidemic or an anhealthy season, but should all be directly interested in zeeping down sickness. It is true that at present we express general satisfaction at a fall in the death-rate; but we know all the time that it means a corresponding fall in our own incomes, which makes our satisfaction very much less genuine than it ought to be. Our interest and our duty ought to coincide, whereas under the present system they Eonflict; fortunately for the public, we never hesitate a moment in our preventive efforts, but still it is hard that we should suffer in direct proportion to our success. We should also under the retaining fee system be saved the trouble and expense of making out periodical accounts, and, since all the payments would be made in advance, we should neither incur bad debts nor have to wait indefinitely for payment. I meant to deal with certain obvious objections to this proposal, but, as this paper is slready longer than I intended, I will leave them for you to 8ake and will ask permission to reply to them later.
It would, of course, be absurd to anticipate that this form of contract will ever entirely supersede the present system, which must always remain applicable to many cases. submit, however, that fifty or a hundred patients making fixed adequate annual payments would form an excellen backbone for any practice, and would be a blessing both to him that gives and him that takes.

In a recent judicial utterarce it was held that reputable medical practice is such as is considered to be reputable by the majority of the practitioners of repute in the neighbourhood. If this society does not in this the first year of its existence include the majority of the local practitioners, I feel sure that it will soon do so. Let us, then, take at the outset a high tone in all questions of professional ethics and professional remuneration; let us decide clearly and definitely what is legitimate practice and what is not, and, having decided, let us apply our decisions fearlessly to individual cases.

\section{OBSERVATIONS ON FOUR HUNDREI CASES OF ANCHYLOSTOMIASIS.}

\section{BY F. M. SANDWITH, M.D. DURH., \&c.} PHYSICIAN TO THE KASR-EL-AINI HOSPITAL, CAIRO.

History.-About 3450 years ago, some two centuries before Moses was learning all the wisdom of the Egyptians and qualifying to become a famous sanitarian, a medical papyrus was written in the Hieratic character embracing in an encyclo. pædic form the knowledge at that time of Egyptian teachers. This oldest of all books on the art of medicine came into the hands of Professor Ebers at Thebes in 1873 and has recently been translated into German. Dr. Joachim ${ }^{2}$ fully agrees with Scheuthaner ${ }^{3}$ that the anæmia due to the anchylostoma was well known to the physicians of those days under the names of AAA and UHA. The papyrus describes accurately among the symptoms heart weakness, palpitatio and stabbing cardiac pain, constipation, cedema of the legs and a weight in the body pressing heavily, with other diges tive troubles. But, most wonderful of all, a remedy is prescribed for a patient who has in his abdomen worms which are produced by the $\mathrm{AAA}$ disease. Is it possible that this can refer to anchylostoma, which we now believe to be the cause, or to the occurrence of other worms in the bodies of the sick Entozoa of many kinds are extremely common in all tegptian patients to-day, and there is no reason for thinking they were not equally common in the days of the Eighteenth Dynasty. Within modern times the earliest mention of this specia anæmia was from Brazil in 1648 and from the West Indies and Guiana at the beginning of the eighteenth century. I Europe the disease was first noted among the miners of Anzin in 1802, but it was not until 1843 that Dubini at Milan first discovered the anchylostomum duodenale. Pruner (1847) Griesinger (1851), and Bilharz found the parasite ver plentiful in Egypt and successfully proved that it was the cause of the so-called tropical anæmia. In $1833 \mathrm{M}$. Hamont a veterinary surgeon, wrote of "cachexie aqueuse" in Egypt, which was very common among the peasants and soldiers, and which, after lasting some years, was nearly always fatal He describes some of the post-mortem appearances and ridicules the treatment of the French physicians, who among other things ordered twelve leeches to be applied to the abdominal walls of men dying from anæmia. With the excep. tion of a few cases reported by Sonsino about 1880 the disease has hardly been investigated in Egypt of late years. The principal object of this paper is to draw the attention of my Egyptian colleagues to a disease which is sapping the life of the peasant class and to the means of curing it.

Geography. - Since 1878 ancbylostomiasis has been found to be spread all over the north of Italy and in Sicily and Sardinia. In 1879 its discovery among the St. Gotthard workmen excited the interest of the scientific world. The disease has been found arnong miners in Spain, among brickmakers in Germany (Cologne and Bonn), in Belgium, and the Yetherlands, and at the Schemnitz mines in Hungary, where it was

Written for the Eleventh International Medical Congress held in Rome, 1894.

2 Papyros Ebers, aus dem Aegyptischen zum erstenmal rollstindig ubersetzt, von Dr. Joachim. Berlin, 1890.

3 Virchow's Archiv, Band 1xxxv.. 1881. See also Dr. Finlayson's erudite lecture, Brit. Med. Jour., 1893. 
successfully stamped out in 1881 by enforcing cleanliness among the miners. In France it has been found at St. Etienne, Valenciennes, and Commentry. It is worth noting that anchylostomiasis has, as yet, not certainly been found above latitude $52^{\circ} \mathrm{N}$., and also that above latitude $47^{\circ} \mathrm{N}$. the parasite apparently can only flourish in the sheltering warmth of mines. Besides Egypt, reports have come from Africa, from parious places on the West Coast, stretching from the Senegal to the Congo, and from Abyssinia, Zanzibar, and the Comoro islands. In Asia discoveries of this disease have lately been made in Cochin, Lower Bengal, Assam, Burmah, Ceylon, Borneo, Japan, and the Malay Archipelago. On the American continent the disease has been found in some of the southern United States, the Antilles, and in Bolivia and Peru, thus stretching its area of prevalence to $30^{\circ} \mathrm{S}$. latitude. In Eygpt itself my hospital cases show that the disease is very widely spread, for I have had peasants from every province in Upper and Lower Egypt, those near Cairo being naturally most often represented. I hoped at first that the patients might come from only a few villages, where the disease could be treated energetically and perhaps stamped out, but my notes tell of more than fifty villages affected in Upper and more than fifty in Lower Egypt. The figures show that 41 per cent. of the patients came from Upper Egypt, 48 per cent. from Lower Egypt, and 11 per cent. from Cairo and its suburbs. It is impossible to know what amount of the population is affected, but the statistics of the Recruiting Commissions for 1892 are worth quoting. Nearly every adult male peasant is liable to conscription, and the conscripts are medically examined in their villages. In Upper Egypt 5988 men were called, and 200 , or 33 per cent., were rejected for anæmia. In Lower Egypt 661, or 62 per cent., were rejected from this cause out of 7420 men. Every province furnished anæmic rejections, but Menoufieh came highest on the list with 13.9 per cent., while $I$ find from hospital statistics that no less than fifteen villages in that province are infected. The recruiting medical officer, who is an Englishman, only rejects those who are obviously too anæmic to serve with the colours, accepting many who are already the hosts of the blood-sucking worm. Thus the medical reports for the Egyptian army show that in 1890 there were 114 admissions to hospitals for anæmia, in 1891107 admissions, and in 1892170 admissions. In 1891 22 soldiers were invalided from the service for anæmia, and 65 in 1892, besides which there was one death. The number of admissions for debility are equal to those from anæmia and doubtless include many cases of anchylostomiasis. My patients came from all parts of Egypt, except some of the seaport towns, but I have no doubt the complaint could be found in all of them if properly searched for. For instance, no anxmics came to me from Suez, but Dr. Creswell assures me he has treated three cases there, all earth-workers from pillages in the Delta. He also found the worms in the body of a man from Suakin, who died shortly after admission to the Government hospital. From Alexandria I have had only one patient, a blacksmith, but the disease is very well known to Dr. Schiess Bey at the Government Hospital there. Nomenclature. - European and Egyptian physicians are usually content to call this disease "anæmia" and to treat it without special reference to its causation; but the natives are apt to call it, as in other countries, "mal de cour," and almost every new patient begins the catalogue of his symptoms by putting his hand on his epigastrium and saying "my heart." The only native name for anæmia is rihaqàn, or "the yellows," from an Arabic word meaning saffron.

Age.-Nearly all my patients were in the prime of life, between twenty and forty years of age; but as no Egyptian ever accurately knows his own age that has to be guessed for him. The youngest case seen was a boy aged six years, after which came several boys of about twelve years, there being altogether 48 cases between ten and twenty. Between twenty and thirty there were 170 cases, and 140 more between the years thirty and forty. From forty to fifty the patients diminished to 21, from fifty to sixty there were 15, and above eixty there were only 7 , making a total of 402 patients.

$\delta \in x$. - Ont of 402 cases only three belonged to the female sez - two children aged twelve and thirteen, and the other a fellah woman who worked in the fields with her father. I beliere many peasant women suffer from anchylostomiasis, but they have not yet learned to apply for hospital relief in the same proportion as the men. I have often searched for the

Surgeon-Major Giles publisbes the case of a girl aged four, rerified at the necropsy and complicated by malaria and tubercle of one lung. parasite in cases of anæmic women in Cairo without finding it, such anæmia obviously depending upon want of fresh air, bad food, prolonged suckling, \&c.

Nationality. - The bulk of my patients were Egyptians, and I have not yet met the disease in a Bedouin, though I once saw it in a negro who worked for a Bedouin master near the Pyramids. I have seen comparatively very few negro cases, and this experience is borne out by the recruiting officers of the Egyptian army, who tell me that "anæmia among the Soudanese is much less than among the fellaheen, but it does exist to a small extent, and especially among those recruited in the Delta." Moreover, only two cases per annum are invalided for anæmia from the negro regiments, which form one-third of the whole Egyptian army. It must be remembered in this connexion that the blacks are cleaner in their habits than the Egyptians, and also that they do not lend themselves so easily to agricultural pursuits as the natives of Egypt.

Occupation.-My hospital patients came from the poorest classes of the community, and I know nothing about anchylostomiasis in higher social scales, ${ }^{5}$ but I can conceive no reason why anyone should not be subject to it, provided he swallows some earth containing living embryos. Among 200 men of whom I have taken careful note no fewer than 190 were accustomed to work in more or less damp earth with their hands. The actual figures are as follows: Fellaheen or agricultural labourers working all day in the fields with their hands and with the hoe, which is their one tool, 152 ; masons' or bricklayers' labourers building walls with mud bricks and mud cement, 18 ; scavengers of street refuse and of cesspools, accustomed to emptying with their hands the dry contents of the latter, 7 ; pedlars who dig up and afterwards sell unwashed regetables, such as onions and radishes, 7 ; limestone carters, accustomed to act as scavengers on their return journeys to the desert hills, 3 ; a gardener, a fisherman in mud, and a "shadouf" worker at the Nile bank completed the 190 cases. The remaining 10 men were 1 coffee-stall keeper, 3 readers of the Koran, 1 blacksmith, 1 street shoe-black, and 4 street beggars, 2 of whom announced that they were habitaal earth-eaters. All these denied ever having done a day's work in the fields and, excepting the Koran readers, were all townsfolk. These latter, like the beggars, live on food which is given them by the well-to-do. Outside the large towns nearly every representative of the lower classes works in the fields, either for his own profit or for hire. Some 20 policemen incapacitated temporarily by this disease have passed through my hands, all of whom dated their illness from periods of their life when working as fellaheen. Some of these had joined the police direct from their villages, and others had previously passed through the army and had been treated for anæmia several times in the chief hospital of the Fgyptian Army.

Cause. - All that is required to produce anchylostomiasis in man or monkey ${ }^{6}$ is to introduce into the stomach a mioroscopical quantity of earth containing embryos of the parasite in its rhabdite form and then to patiently await the result Muddy water, such as the Egyptians prefer to drink, will act as a vehicle if the embryos have not been too long in it. Unwashed vegetables, fouled by human ordure, and especially unwashed hands coming straight from tilling contaminated soil, are probably responsible for much of the infection. The calls of nature are obeyed by both sexes in close proximity to the huts inside or outside which they eat, and doubtless embryos are often transferred from the feet to the month of those who sit cross-legged at their meals. European textbooks still refer to water as the medium through which the parasite reaches man ; but Surgeon-Major Giles has examined fifty-six specimens of water from wells and ponds of villages affected by anchylostomiasis: sixteen of these he found by chemical and microscopical examination to be "bad" or "very bad," yet on only one occasion did he find a rbabdite of donbtful origin in water. However, it is quite

5 THE LANCET of Feb. 1st, 1890, published an instructive tale of a man, apparently well-to-do, who fell ill of anæmia in Central India in 1885. He was sent to Australia for his health, saw sevtral physicians in London and elsewhere, and improved under iron tonics. In 1889 after many ineffectual attempts to resume work. he was so prostrated by diarrhcea and weakness that he entered a hospital at Heidelberg, where 127 ankylostomata were discovered and the patient was cured. 6 Report on Kála-azár and Beri-beri, by Surgeon. Major Giles, I. M.S Shillong, 1890, p. 82 . Five monkeys were fed with infteted earth; two were killed and many anchylostoma were found in their duodenums, and one died apparently from the parasite, but the duodenum was not examined by an expert. The rewaining two monkeys had no ova ir their dejections four months after they had swallowed the infected earth. 
possible that Egyptians may occasionally infect themselves by their habit of rinsing their mouths with stirred up muddy water. Leichtenstern ${ }^{7}$ fed men with rhabdites and found eggs in their fæces four or five weeks later. Fortunately, continued exposure to the sun's heat during dry weather kills the embryos, or it would be possible for the parasite to do much more harm than is now done in Egypt. The fellaheen, who seem unconsciously to devote their lives to encouraging their entozoa, are often eaters of earth, like the anæmic negroes of the West Indies and Guiana ; 26 per cent. of my cases confessed to eating it, though most of them allowed that it was a bad habit and induced anæmia. They call the Nile mud "teen ibliz" ( $\pi \eta \lambda \delta s$, mud), and apparently have some old superstition that the soil, so fertile to vegetation, cannot but be beneficial to the human economy. Chlorotic and pregnant women often eat earth, as also the women who clean the corn after threshing. There is, too, a curious custom connected with earth eating which I have never seen mentioned. On the day of maximum

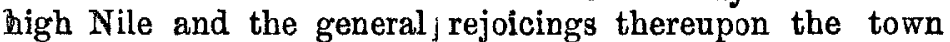
crier, who is on the look-out for backsheesh, presents " teen ibliz" with a lemon to the inhabitants for luck, and many of them eat of it.

Definition.-I ventare to propose the following as the definition of anchylostomiasis : an insidions wasting disease, characterised by progressive anæmia without apparent cause, and by digestive and nervous deterioration, occurring chiefly in earth and brick labourers of warm climates, caused by the presence in the duodenum and jejunum of a blood-sucking Thabditic nematode worm, occasionally proving fatal in protonged cases, but capable of care upon removal of all the parasites, and capable of prevention by scrupulous cleanliness.

Diagnosis.-The anæmia is so marked that there is seldom any difficulty in recognising it, and therefore this symptom is well known to all physicians who have patients among the fellaheen; but the disease itself is rarely recognised in Egypt, for a generation has arisen which knows not Griesinger, and under ordinary circumstances the worms are not to be found in the evacuations. Even after thymol and a purge have been given to a patient fasting care and patience are required to find the worms. This can easily be done after submitting the fæces to several washings with clean water and examining the final deposit. The worms, which are naturally white, are generally discoloured by the fæces, and must be carefully distinguished from any accompanying oxyurides. It will be found that thymol has removed most of the frcal odour. The microscope furnishes the readiest means of discovering the parasite, for in most cases eggs can be found in a tiny portion of the suspected fæces, which, to make the examination more agreeable, may be washed in a test-tube with a weak solution of carbolic acid. In any case where anchylostomiasis is suspected, in spite of the absence of ova under the microscope, a cultivation experiment in damp earth exposed to the air would establish absolutely the presence or absence of the parasite.

Symptoms - These may be grouped into three classesthose affecting the digestive, circulatory, and nervous systems. They usually affect the patient in the above order, but most eases are so far advanced before they come under treatment that all three systems are affected. The worms are voided so seldom with the fæces that patients never know that they are suffering from entozoa, unless they happen also to be the hosts of ascaris, oxyuris, or tænia. Gnawing, throbbing pain in the epigastrium is the first symptom complained of, ehiefly because it is constant, whereas severe colic and borborygmi of the intestines are only present from time to time. The appetite is invariably affected, sometimes ravenous at the beginning, but later it is always capricious and diminished. The English nurses tell me that anchylostoma patients are always begging for medical comforts or cigarettes, even in the middle of the night, when other patients are asleep. A mong 40 men carefully cross-examined 16 said their appetite was once greatly exaggerated, 16 pleaded diminution from the beginning of their illness, and 8 believed their appetite was normal until the anæmia became very marked. I have already referred to earth hunger, sometimes the mause and sometimes the effect of the illness. Vomiting and nausea were rarely complained of. Constipation, when not under thymol and purgative treatment, was a very constant symptom in hospital; 60 per çent. had

7 Deutsche Med. Wochenschr., Oct. 18th, 1888.

Hirsch: Geosraphical Pathology, English edition, vol, ii., p. 813. suffered for a long time from obstinate constipation, 28 per cent. had had diarrbcea before admission, and 12 per cent. had no recollection of being troubled with either. None of the figures depending upon the memory of the patients must be taken as absolute truth, as the intelligence of many is of a very low order. Diarrhœe and even dysentery are not uncommon in very advanced cases, especially those compli. cated by bilharzia ulceration in the rectum, and unless the patient is robust enough to support thymol such cases are apt to end fatally. However, I have had the satisfaction of curing some cases of anchylostomiasis which had been unsuc. cessfully treated elsewhere for several months as chronic dysentery. Flatulence of the lower abdomen has been mentioned by Dr. Lutz as a common symptom. I found it present to a slight extent in one-third of the cases. The urine is not unlike that of ordinary anæmia, neutral or alkaline in equal proportion, and rarely acid, pale coloured, with specific gravity ranging from 1010 to 1015 . A trace of albumen was present in all the most advanced cases without casts under the microscope. Pain in the head was generally referred to the temples, while in the knees there were invariably present great weakness and some pain, and occasionally there was, in addition, pain in the shoulders. Giddiness is another very general symptom, and it is this, as much as anything else, which compels them to give up work. Palpitation over the heart, in the epigastrium, and in the temporal arteries is sure to be present in bad cases, while the anæmic murmurs of the heart and neck are solely dependent upon the degree of anæmia and can be banished by a prolonged course of iron. Hypertrophy of the heart was noted and verified after death in some of the advanced cases. Dyspncea and noises in the ears were present, as might be expected with marked anæmia. CEdema of the legs, like albuminuria, is only to be seen in the worst cases, and some of these had general cedema when admitted in a dying condition. The tongue was extremely pale, the mucous membranes were excessively white, the face had an unhealthy yellow pallor, very different to the ruddy brown of the peasant in health, and the bloodless nails testified to the blood containing not more than half the normal number of red cor. puscles. The skin is always cold and the temperature before thymol is given generally subnormal in uncomplicated cases. After excluding any fever produced by concurrent diseases and any defervescence caused by thymol I find that onethird of my patients had a normal temperature during their stay in hospital, but that two-thirds had a distinctly subnormal range, varying from an average of $36.3^{\circ} \mathrm{C}$. A.M. to $36.9^{\circ}$ C. P.M. Many of these patients when convalescent had an increase of half a degree night and morning. Surgeon. Major Giles suspected that many of his patients in Assam had suffered from fever at the onset of their malady, and he was confirmed in this impression by observing pyrexia in the monkeys fed on anchylostoma embryos. After eliminating all those who had fever while in hospital, or a history of intermittent fever or any enlargement of the spleen, I found that 68 per cent. of the remainder stated that their troubles had begun with a few days' fever. The eyes of patients show a pearly white conjunctiva, singularly in contrast with the yellow colour of the face. Dr. Scott kindly examined several men for me with the ophthalmoscope, and found in balf of them a normal fundus and in the other half a fundus verg pallid. The refraction tests showed astigmatism in many cases. I have never found any retinal hæmorrbages, epistaxis, or general tendency to hæmorrhages, but in two cases there was melæna while under treatment. The face of the patient is characteristic, though it is difficult to describe bis discontented, harassed expression, which sometimes changes to a ready smile after a month's stay in hospital. The worst cases are those which are always asleep and cannot be interested in anything when they are awake. On the whole, sleepiness is decidedly a symptom. Dense stupidity, associated sometimes with reiterated demands for a favour already granted, show that the bloodless brain is affected in all advanced cases, and at least three times I have found a condition of weak-mindedness which would have warranted the patients being sent to the lunatic asylum. Debility and wasting are of course important symptoms, but it must be remembered that when a man is so weakened by the disease that he cannot work be ceases to earn money, and his food-supply becomes limited. In fact, it is very often poverty which brings the patient to the hospital. The average weight of 100 grown men upon admission to the hospital was $117.5 \mathrm{lb}$. The average height was $5 \mathrm{ft}$. $5 \frac{1}{3}$ in., which by Danson's tables should scale at least $135 \mathrm{lb}$. Of 
the patients who stayed in hospital more than two weeks 70 per cent. gained weight, 22 per cent. lost weight, and 8 per cent. remained stationary. The average loss of weight was $3.2 \mathrm{lb}$, and was, of course, caused by the necessary starvation, thymol, and purging. The average gain of weight was $54 \mathrm{lb}$, some gaining as much as 15lb., $17 \mathrm{lb}$., 18lb., and 201b. Absence of patellar reflex is not surprising in cases of general debility and muscular weakness. In 35 per cent. of cases examined the reflex seemed unaltered, in 48 per cent. it was completely absent, in 5 per cent. it was decidedly diminished, and in 12 per cent., all of which were early cases, it seemed to me to be a little exaggerated. Impotence seems to be a decided symptom of anchylostomiasis. Out of 38 men specially examined on this point 24 had completely and 5 had almost entirely lost their virile power, while of the remaining 9,5 , aged from nineteen to twenty-five, had their paberty considerably delayed.

Examination of the blood. - I have notes of 173 cases in which the blood-corpuscles were counted on admission to hospital. In only three patients were the red corpuscles found to exceed $4,000,000$, and even then the excess was extremely slight; 23 per cent. numbered between $3,000,000$ and $4,000,000$ to the cubic millimetre, 46.8 per cent. varied from $2,000,000$ to $3,000,000$, and 283 per cent. had less than 2,000,000 red blood corpuscles. The minimum recorded was 930,000 in a patient who afterwards did well. The average gain of red corpuscles during stay in hospital of these cases was $1,290,000$, and could have been much more if it had been possible to keep the patients for a longer time. The least gain recorded in any one patient was 310,000 , while ten patients gained over 2,000,000 during their stay. The youtbs seemed to have the most recuperative power in this direction, and I recorded an increase of 2,542,000 in a boy aged eighteen years. Another boy, aged sixteen, daring one month gained seven pounds in weight and $2,208,000$ red corpuscles, while the Alexandria blacksmith in six weeks gained eleven pounds weight, and raised the number of his red corpuscles from $1,054,000$ to $3,875,000$. It is right to mention that the corpuscles were counted by two house physicians under my guidance, but that, though the rule was to take the average of ten squares, it was not always possible to take the average of more than six squares in counting by the method of Thoma-Zeiss. The average number of white corpuscles upon admission was 10,360 and the average increase in hospital was 5370. Gowers' hæmoglobinometer showed an average of 26 per cent. upon admission, the numbers varying from 10 to 54 per cent. of hæmoglobin. The increase of hæmoglobin in hospital ranged from 22 to 32 per cent. and probably continued when the men became out-patients. As a further blood test, Dr. Kaufmann examined twenty typical cases for me to determine the volume of the red corpuscles. ${ }^{9}$ Healthy men were found to have from 45 to 50 per cent. by volume, but the anæmic patients had only from 15 to 43 per cent., the average of all being 25 per cent. This average corresponds very fairly with the average of red corpuscles by enumeration. One patient increased in bxmoglobin from 23 to 45 per cent. and in volume from 16 to 43 per cent. in a fortnight. Another patient's hæmoglobin was raised from 35 to 67 per cent. in two weeks and his volume of red corpuscles from 31 to 45 per cent.

Average stay in hospital. - The last 100 of my patients spent in the hospital wards periods varying from fourteen to seventy-six days, the average of the whole being thirty days. Upon leaving the hospital they were cured of their parasites, but not entirely of their anæmia. Some were discharged in order to make room for other inmates, but most of them felt so much better in health that they clamoured to be allowed to return to their work.

Duration of illness. - Nearly every patient said he had been ill two or three years before admission. I find among my notes 29 cases, uncomplicated by other diseases, where the patients said they had suffered for more than three years ; of these, $13 \mathrm{had}$ been ill for four years, 6 for five years, 3 for six years, 2 for eight years, 2 for nine years, 2 for eleven years, and one vowed that it was fifteen years since the commencement of his symptoms. It may safely be said that during these long intervals of time very few patients had any rational treatment.

Complications and concurrent diseases. - It is very rare to perform a necropsy upon an Egyptian of the peasant class

${ }^{9}$ Schulmeister's centrifugal top machine was used with Paofessor Gatrtner's bæmatocrite. This method has the great advantage of being very rapid compared to the enumeration of corpuscles by the microscope. without finding various entozoa, and the anchylostoma patients are no exception to this rule. The distoma brmatobium of Bilharz is so common among men and boys that its presence is not always noted, and my cases probably included more than the 80 cases of which I have notes. At one necropsy there were 40 worms in the blood of the veins of the liver. In experimenting on cases of bilharzia with thymol (so far unsuccessfully) I have often found anchylostoma though the patients had no symptoms or appearance of anæmia. Oxyuris vermicularis was present in half the patients, and was usually completely expelled by the first dose of thymol. Though this worm is so common in Egypt I hardly know whether it produces any bad effects. Ascaris lumbricoides was noted in 15 cases after the exhibition of thymol, and perhaps was present more often. Thymol expels it quite as well as santonine. Tænia mediocanellata was present four times and is not well acted on by thymol. Trichocephalus dispar was only found in two of my cases (Surgeon-Major Giles found it in nearly all his Assamese patients). Favus was present in many of the poorer Egyptians. Pellagra existed in 28 cases and being in an early form was cured by the tonic treatment. Intermittent fever occurred in 9 of the cases. I have found anchylostoma in cases of dysentery and of fistula in ano, and have found it in patients who came to the hospital complaining of hæmorrhoids and prolapse of rectum. Albuminuria was present in 30 advanced cases, besides three others in which there was kidney disease Nearly all the fatal cases passed while in hospital urine of uniform specific gravity (1010). Three cases came under my care after they had had lithotrity successfully performed. Chronic bronchitis may be regarded as one of the complications, having been present fifteen times. Ten patients with tubercle of lungs also harboured anchylostoma. I have also found them in isolated cases of cirrhosis of the liver, diabetes, rheumatism, heart disease, leakæmia, disseminated sclerosis, hasheesh delusions, \&c. Beri-beri has a geographical range very similar to that of anchylostomiasis, in spite of the endemic state of the latter in Italy, and this probably accounts for their having been so often confounded. Beri-beri, which would seem to be $\mathbf{a}$ specific peripheral neuritis, has not yet been found in Egypt, and the cases on which this paper is written do not at all resemble the accounts published of beri-beri where it is uncomplicated by the presence of anchylostoma. Moreover, I have had the advantage of showing several groups of $\mathrm{my}$ patients to physicians well acquainted with beri-beri in the Straits Settlements and India, and all of them have failed to find the characteristic signs of that disease.

Mortality._- Of patients nominally under my care 89.5 per cent. were cured or greatly relieved, 25 per cent. were unrelieved, and 8 per cent. died. The total number of necropsies of which I have notes is 26 . Of these, 10 were admitted to the hospital dying, and they died within two or more hours. These were generally found by the police lying in the streets, starved with cold and hunger, and in the last degree of exhaustion. Eight died after treatment by thymol, and 8 others were treated in the hospital for other diseases, such as gastritis, enteritis, kidney disease, dysentery, and general tuberculosis. One man came from the surgical wards after an excision of the lower jaw for cystic enchondroma. Besides thirteen bilharzia worns in his portal vein his intestines contained three ascarides, three oxyurides, and 118 anchylostoma, fifty of which were still attached to the jejunum. Of the 8 thymol cases 2 died, I think, in consequence of the thymol eleven hours and fortyeight hours respectively after taking the dose ; both these men had previously had thymol without bad effect, but they were both in a miserable state of exhaustion and debility. I do not think that thymol accelerated the death of any of the remaining 6 cases. The number of days which elapsed between the last exhibition of thymol and death was five, six, nine, thirteen, fifteen, and nineteen respectively. Three of these cases were over sixty-five years of age. Most of the fatal cases had loud anæmic murmurs, markedly subnormal temperature, slight general oedema, albuminuria, and great mental weakness. The actual oanse of death was exhaustion from ntter absence of rallying power. It is difficult to believe that the pathological effects are induced only by hrmorrhage from the daily suction of scores or even hundreds of worms. In addition to the loss of blood there are general thickening and degeneration of the duodenum and jejunum, and consequent interference with normal digestion, then non-assimilation, and eventually a process of slow starvation. It is also worth of consideration that there may be in prolonged cases some 
self-poisoning from the great number of bites in the walls of intestines containing ill-digested and perhaps decomposing food.

Post-mortem appearances. - Some of the earlier necropsies were made by myself, the later ones by Dr. Kaufmann. The muscles were in one case described as of normal colour, but in all others they were very pale. There was usually a great absence of subcutaneous fat. The lungs were very pale and cedematous in all cases, and all the organs were extremely bloodless. In one case there was noted cedema of the glottis. The heart was found to be hypertrophied ten times, and was very small twice, generally pale-brown in colour, and on three occasion there were marked changes in the mitral valve. The most common abnormality in the liver was a brownish-yellow fatty appearance. In one case there were several abscesses and the liver weighed 3700 grammes, and in one patient there was well-marked jaundice. The spleen was enlarged in one-third of the necropsies. The kidneys invariably showed some change, though this was often much more marked in one kidney than in the other. They were very pale in twenty-four patients, three of whom had several small cysts. Of the remaining two patients one had granular kidneys and the other had cysts, but the kidneys were of normal colour. The brain was always exceptionally white, and in one case there was recent apoplexy. The small intestines showed, of course, the most important changes. As a rule, there were many hæmorrhages and bites in the jejunum and ileum, but in one of the cases, where the bites were carefully counted, there were only six in the jejunum and ileum, and no worms were found. In another case, however, there were 575 bites in the small intestine, besides 250 anchylostoma. In yet another there were 100 bites, the farthest of which was four metres and a half from the pylorus. In only two cases was there much liquid blood in the intestine. I have not observed the constant changes in the mucous membrane of the stomach described by Surgeon-Major Giles. The great variability in the number of anchylostoma found at the necropsies is interesting. In seven cases, all treated by thymol during life, no worms could be found. In an eighth case, also treated by thymol, but insufficiently, there were ten worms. The remaining eighteen cases had not had the advantage of thymol. Six of them, nevertheless, were found to have less than ten worms, and in 2 of these corpses only one worm was found in each jejunum. Three other cases numbered 20,40, and 50 worms ; but the remaining 9 had numbers varying from 170 to 381, terminating with the maximum record of 863.10 On that occasion the mecropsy was made seven hours after death, and the worms were scattered from a point one inch beyond the pylorus for the length of three metres; 217 of the 853 were still attached to the intestine and were surrounded by much bloody mucus, while 646 were lying free in the intestine. Sixteen of the latter were still alive, and one couple were in copulation. ${ }^{11}$

Next, the position of the worms deserve notice. It was quite the exception to find any parasites in the duodenum. Can it be that when the duodenum becomes thickened and riddled, as it were, with the ravages of former generations the anchylostomum fastens by preference on to the jejunum? Some such cause as this suggestion of gradually shifting the pasture is required to explain the interesting fact that it is not the most advanced cases of anæmia which always yield the largest quantity of worms. In such cases the parasite must not only have to burrow extra deep, but the blood when reached is of course deficient in quantity ; or is it that the half-starved worms are dislodged by repeated attacks of diarrhœa? The furthest feeding ground that I have ever seen was 630 metres from the pylorus, where there was a worm firmly attached $;{ }^{12}$ but as a rule the attached worms are all within two metres of the pylorus and have their heads and sometimes half their bodies buried in the mucous membrane. It is often impossible to dislodge them by a strong stream of water, and they must then be pulled out by forceps. I exa10 Ernst of Cologne reports a case (Deutsche Med. Wochenschr.,
April 12th, 1888) of a brickmaker aged thirty. Ave who was admitted April 12th, 1888) of a brickmaker aged thirty-five who was admitted to hospital dying of anæmia without œedema. His red corpuscles nere found, being At the necropsy as many as 2763 anchylostoma were found, being 1269 males and 1494 females. Only 81 worms were still attached to the intestine. The greatest quantity of worms, both
attached and free, were found between two and three metres from the

attached

11 Lutz, among 14,000 worms, found only one couple in copulation (Schmidt's Jahrbücher, Band cexviii.,; Heft 1, p. 38)

12 Dubini has only once seen the worm in the ileum. The nearest feeding ground seen by me was 24 centimetres (91 inches) from the pylorus. In that case there were 100 worms attached and 281 detached, besides oxyurides. mined about fifty cases to see the proportion of male to female worms and found it to be 56 to 44 per cent. This is not in accordance with some of the anthorities, ${ }^{13}$ who say that males are always more rare than females, and that males are less influenced than females by the action of expellent drugs.

Treatment. - The native remedies for the disease are barbarously crude. As no one knows the real cause of the disease no attempts are made to expel the parasite. Most patients bear on their heads, legs, or epigastria the scars left by the barber's application of red-hot sickles or nails to relieve pain. One man came to the hospital after the rough treatment of the actual cautery with a large slough on his back, in the midst of which a small artery was spurting. Some patients have in addition setons placed in their ears and at the pit of the stomach, and others have been bled from the arm or from under the tongue. A few men have been advised to eat for their obvious anæmia iron filings mixed with sugar, but in this remedy they have very little faith The rational treatment is, of course, twofold-viz., to expel the worms and to treat the anæmia. Before I ever heard of thymol as the specific vermifuge for this disease I went through a weary apprenticeship of failing to get rid of the parasite with other drugs. ${ }^{14}$ When I first learnt the powers of thymol on the anchylostomum, I experimented on a dozen patients with santonine, male fern, \&c., before giving that drug. In every case the bulk of the worms were not removed until after the administration of thymol. Two patients roided 324 and 120 anchylostoma respectively after thymol, though not a single worm had been expelled by means of other drugs. But for the last three years I have looked upon it as a waste of time to administer any other anthelmintic than thymol for this parasite. Perhaps the most successful dose I ever prescribed was on May 12th, 1892, when a rickety, syphilitic peasant, after 4 grammes of thymol, was rid of 480 anchylostoma, 750 oxyurides, and 15 ascarides. On May 19th the thymol was repeated, and twenty-two anchylostoma were passed. On May 26th eighteen more appeared after a similar dose. On June 2nd there were three more, and on June 8th there was a last detachment of five. Two more doses of thymol were given without result, and eggs ceased to be found under the microscope. In order to see whether thymol had cleared out all the round worms a dose of santonin was given on June 5th without any effect. In 229 patients I have induced students to count the numbers of anchylostoma voided after the first dose of thymol. There were 14,190 of this species alone, giving an average of 62 per man. The largest numbers met with were $350,372,480,483$ and 600 . On seven occasions no worms at all were found, in spite of eggs, under the microscope, but in three or four of these patients a second dose of thymol produced a very few specimens. Now one word about the number of doses of thymol required to completely eradicate the parasite. It is true that the bulk of them are brought away by the firs dose, but there are invariably many stragglers behind and it seems dangerous not to attack them. In 184 patients I was able to prove the absence of worms by giving at least two, and sometimes more, doses of thymol after the last appearance of the parasite in the stools. The average number of doses required proves to be $2 \cdot 6$. Forty-two men were cured after only one dose, 58 after two, 42 after three, 25 after four, 9 after five, and 4 after six doses of thymol In two cases, however, the parasite could only be entirely dislodged by seven attacks, and two other cases required eight doses of thymol. In the event of patients being treated ontside a hospital, it will, therefore, be advisable to give the thymol treatment on at least three occasions. The dose of thymol is of considerable importance. I quite agree with Giles and other writers that small doses are valueless. used at first to give, as recommended, six grammes at intervals of two grammes every two hours, but to prevent unnecessary collapse I have for the last year only given four grammes a an adult dose-viz, two grammes at 8 A. M., and the remairder at $10 \mathrm{~A} \mathrm{M}$. I am of opinion that four grammes are as efficaciou as six, and are certainly less dangerous. Warned by the death of at least one of my patients immediately after digesting the thymol, I have always administered to feeble men twenty-five grammes of brandy with each two grammes of thymol, with

13 Traité de Zoologie Médicale, vol. i., p. 765. Par R. Blanchard. Paris, 1889.

14 So lately as Nov. 25th, 1891, the Semaine Medicale tells of cases of anchylostomiasis at Lyons treated with 15-gramme dases of extractum filicis maris liq., and death with tetanic symptoms. Professor Lépine thereupon recommended that the maximum dose should not exc zed 8 grammes. 
the happiest results. For a day before and a day after the thymol the patient is kept on a diet of milk and soup. I began by giving a purge before and after the thymol, bat for a long time now I have omitted the preliminary purge as being unnecessary and as contributing not a little to the patient's exhaustion. At twelve, noon, two hours after the second half of the thymol, sulphate of magnesia or castor oil, the latter to be preferred, is given. The stools were nsually examined at 4 P.M., and again at 8 A.M. the next morning-i.e., eight hours and twenty-four hours after the first swallowing of the thymol wafers. I have taken notes of 50 cases to see whether it be necessary to examine the motions of both days. I find that 1301 worms were found np to 4 P.M., and that 444 were passed between 4 P.M. and the following morning. Moreover, upon ten occasions there were no worms in the afternoon, though some appeared later in the stools, whereas twenty times there were worms at the afternoon examination, and none the following morning. Therefore, if impossible to examine several motions, it would appear more important to examine those specially which are passed from six to eight hours after the early thymol. Thymol if given without brandy is probably very insoluble in the stomach and duodenum, and Giles says that he seldom fonnd any worms until twelve hours after the earliest thymol. Occasionally patients vomited after swallowing the drug, bat as a rule they retained it perfectly and evidently had some faith in its properties, for they used to ask for an extra dose of it while convalescing. Large doses of thymol have poisonous effects upon the system, not unlike those pro،áced by carbolic acid. The temperature is lowered one or even two degrees Centigrade, and both pulse and espiration are slowed. The patient remains for a few hours collapsed, giddy, and faint, and has to be kept lying down; but at sunset he is quite well again and asking for food. The following case is a typical one in a very anæmic man :-Jan. 14th, $1892: 6$ A.M., temperature $375^{\circ}$, pulse 80 , respiration 19 ; the patient was in his usual state, and was given two grammes of thymol; 7 A.M., temperature $36^{\circ}$, pulse 80 , respiration 19 ; the patient said he had slight nausea, giddiness, and colicky pain at the epigastrium; \&.M., two grammes more of thymol were given; 9 A.M. , temperature $35.5^{\circ}$, pulse 70 , respiration 17 ; great giddiness; the patient could not stand or walk; he was very sleepy and talked like a drunken or very sleepy man ; 12 A. M., symptoms much the same; the patient perspired while asleep: 2 P.M., temperature $375^{\circ}$, pulse 75 , respiration 18 ; the patient was apparently quite well again and said he did not mind the thymol, excent that it made him lose consciousness. The following case is worth quoting very briefly because of the low temperature and of the disease not having been previously recognised. Dec. 29th, 1891: A fellah was admitted from the Barrage, near Cairo, complaining of giddiness, pain in bis head and epigastrium, and weakness of knees. He was extremely anæmic, and his face very yellow ; but his nails, though very white, showed a faint pink tinge. He seemed only half-witted; but I learnt that he had been ill for three years and had been treated by rustic quacks for hæmorrhoids, having also been treated four times in a Government hospital for dysentery. His motions, which were five in the twenty-four hours, contained many anchylostoma eggs. He had a loud anæmic murmur; the liver and spleen were slightly enlarged; the urine had a specific gravity of 1013, but contained no albumen. Dec. 30th 7 A.M., one hour after thymol, temperature $366^{\circ}$, pulse 62 , respiration, $20 ; 9$ A.M., after a second lot of thymol, temperature $354^{\circ}$, pulse 58 , respiration 16 ; pupils contracted great weakness, sleepiness, and giddiness; 11 A.M., having now taken six grammes of thymol, temperature $35^{\circ}\left(95^{\circ} \mathrm{F}\right.$.), pulse 46, respiration 16; the patient was collapsed, and brandy had to be freely administered; 2 P M., quite well again ; temperature $36 \cdot 6^{\circ}$. This man was discharged on May 31st, 1892, with good colour and looking happy, though there was still slight mental weakness. His diarrhœa had completely ceased, his weight had improved from $84 \mathrm{lb}$. to $101 \mathrm{lb}$., and his temperature was no longer subnormal. The contraindications for thymol are excessive debility, very low temperature, age above sixty, and advanced disease of heart or any other organ. Boys take it very well in half quantities. If patients return to their former lives after leaving the hospital, as it is certain they will, they will again become hosts of this dangerous worm, but I can recall only one case of a patient treated by several doses of thymol who returned to the hospital still sheltering anchylostoma. This was a boy who also had bilbarzia, and on turning up the old notes of his case I find that he was discharged as "better" from hospital directly no worms had been discovered in his stools after thymol. A more careful search for worms or for eggs might have shown that he was not cured. Bat, on the other hand, several old anchylostomiasis patients have returned to the medical wards for other diseases, and no eggs have been found in their dejecta. As a rule, I have not considered it fair to submit patients to the depressing influence of thymol more often than once a week, but in the case of fairly robust men who were anxious to make no long stay in hospital I have often given it every four days. Isolated cases could, of course, be treated with much more care than I have shown, but for the last year or two I have found a third of my male wards full of anchylostomiasis, and I have been obliged to consider the greatest good of the greatest number. To prevent any possible spread of the disease the evacuations of patients ought to be treated with some disinfectant such as perchloride of mercury, 1 in 500. The general treatment of the anzmic is, of course, of great importance from the very first. The hospital mixed diet, with its meat and better bread, is superior to the food obtained by patients before admission, and contributed greatly to their improvement in health. In spite of the disturbances of the digestive tract, men, unless dying, were always ready to eat ordinary and extra meals. Iron I have tried in various forms, and though some few patients complained of headache at first it was greedily absorbed by the economy. My only desire was to find that preparation of iron which could be taken in large doses and would quickly banish the anæmia. The peroxide can be borne in large quantities, but the microscope proved that the blood was most benefited by the daily supply of one gramme and a half of the sulphate of iron in water in three equal doses. The patients during their stay in hospital were always taking iron, except on the days devoted to thymol. During the winter some of the feeblest patients were given every day a little brandy with advantage. The treatment of other symptoms was too simple to need mention. Tranfusion of blood, or even of a saline solution, I have often thought might be beneficial to cases admitted to hospital in a dying state, but as yet I have not tried this treatment.

Prevention of the disease.-Cleanliness alone is required, but it will be years before education will teach the fellah to wash his hands before eating. In the meantime can the Government do anything to prevent the ingestion of embryos by the Egyptian labourer? A very simple experiment will prove that the embryo, whose staple food is fæces, will die if deprived of fresh air. If, therefore, the inhabitants of infected villages were compelled to dig trench latrines outside the villages, to use these latrines alone, and to cover them daily with a little earth the disease might be stamped out; but anyone acquainted with Egypt knows that even so simple a reform as this would require an enormous amount of inspection. Another point would be to ensure the latrines being exposed to the sun's heat, for, though the embryos are killed by prolonged exposure to the sun, they have been known to live in shaded earth contaminated by fæces for more than six months. Giles recommends ploughing the injected surroundings of villages, so as to bury the embryos..$^{15}$ I do not believe in anchylostomiasis being communicated in a general way by water, but all efforts to purify the water-supply of villages would be a help to remove this disease and its favourite companion, bilharzia. Lastly, the Government, especially with its recruits for the army, the police, and for public works labour, might have all peasants examined more carefully than is at present done for the early symptoms of this disease. Early cases of anæmia can be recognised by a physician before the patient is aware that he has a definite illness, and one dose of thymol can prevent the chronic pernicious anæmia which drags the man to the hospital one, two, or three years after he begins to feel ill. I am convinced that nearly all the anæmia of adult males among the lower orders in Hgypt is due to anchylostomiasis, if those cases are excepted which are obviously caused by some other kind of hæmorrhage or by wasting disease.

Life-history of the anchylostomum.-A very brief account will suffice here, because the adult worm is thoroughly described in Blanchard's book already referred to, and Giles has traced out very carefully the rhabdite changes. I first cultivated embryos in a garden, but afterwards found it more convenient to keep infected fæces and damp earth in glass

15 Pp. 131-135. Also Tea-garden Sanitation, by the same author. 
dishes in a room, the temperature of which during June and July varied from $21^{\circ} \mathrm{C}$. to $24^{\circ} \mathrm{C}$. In fresh freces the ova are usually two- to four-segmented, but may contain eight segments, and on the second day I found several already containing living embryos. On the third day several embryos bad escaped from their eggs. In the young stage they resemble in structure and habits the free-living rhabdites and, like them, go on feeding and growing for a considerable time. They then change their skin either once or several times and enter upon a stage when they cease to take in nourishment and to increase in size, and then they need to become parasitic ; but so long as nourishment in the way of fæces is supplied to them and they are protected from drought or too great heat they will continue to live for months, in the hope of being swallowed by a man, in whose duodenum they can alone develope into adult worms. On the fourth day tbe embryo is almost, and on the fifth day quite, free in its sheath. On the sixth day and later I found empty eggs from which the embryo had just escaped, but it was not until the tenth day that I canght one in the very act of emerging. On the sixth and following days the embryos were of very varying sizes, all very active, and wriggling towards the edges of the cover glass to escape. On the serenth day I could first distinguish that some of the embryos were females. On the eighth day there were on one slide 30 embryos, all alive and of different sizes, the largesized being now obviously male and female. On the tenth day the eggs were suddenly increased in number, from 1 or 2 to 17 upon one slide, apparently rhabditic, but having tbe same appearance as the original ova. Upon the same slide were 27 embryos of various sizes and one ruptured empty sheath. On the elerenth day one slide showed 15 eggs and 25 embryos, all alive but moving very slowly. On the twelfth day there were on one slide $27 \mathrm{eggs}$, 14 dead embryos, and only 2 alive, and those moving very feebly. I then divided the cultivation into two halves-one half to be moistened with filtered water claily, and a new half to be mixed with the fæeces of a healthy man, after negativing anchylostoma by the microscope. On the fifteenth day a slide from the old half showed 5 eggs and 3 dying embryos, while a slide from the new half showed 30 eggs, 6 embryos dead, and none alive On the sixteenth day the old half showed 6 eggs and 4 dead embryos, while the new balf bad 14 eggs and 7 very lively but very young embryos. This new brood had thus been produced by healthy fæces in four days. It is not necessary to give all the daily examinations. On the thirtyfirst day the slide from the old balf still showed $12 \mathrm{eggs}$, one of which was empty, 5 dead embryos, and 2 living ones. The new hali had 34 eggs and 18 embryos, all very lively but not growing. On the fortieth day there were no eggs and only one embryo, dead, in the old half, while in the new half there were also no eggs, but 21 very lively embryos and 3 dead ones, as also one complete sheath. On the fortyfourth day, when I had to leave Cairo, the old half still contained two embryos faintly moving, and one dead embryo, but no eggs. The new half showed four eggs and two very lively embryos on one slide. The addition of fresh frecs would again revive the embryos. The experiment is enough to show that embryos on damp earth in Cairo will live for more than six weeks.

\section{ON EMPYEMA IN CHILDHOOD.}

BY FREDERICK E. BATTEN, M.B. CANTAB., M.R.C.P. LOND.,

MEDICAL REGISTRAR AND PATHOLOGIST TO THE HOSPITAL FOR SICK CHILDREN, GREAT ORMOND STREET.

IN THE LANCET of May 5th, 1894, was published an article recommenỏing incision and drainage of empyemata instead of resection. In the following number a letter appeared from Dr. Sttrges pointing out that better results were obtained by resection of a rib, and in verification of the above statement the following tables have (at his request) been prepared. ' For peimission to publish the following cases I am indebted to Dr. Sturges, Dr. Barlow, and Dr. Lees. 'The cares were admitted to the Children's Hospital, Great Ormond-street, during the period May 1st, 1898, to May 1st, 1894, where it has long been the custom to perform resection in nearly every case. Of 48 cases of empyema admitted during the period above mentioned, resection was performed in 45. The following table shows the age and the number of recoreries and deaths which took place :-

TABLE I. - Cases of Empyema.

\begin{tabular}{|c|c|c|c|c|c|}
\hline No. & \multicolumn{2}{|c|}{ Age. } & Recoveries. & Deaths. & Total. \\
\hline 1 & \multicolumn{2}{|c|}{ Under 12 months. } & 1 & - & 1 \\
\hline 2 & " 2 & 2 years. & 3 & 2 & 5 \\
\hline 8 & $"$ & $"$ & 13 & 3 & 16 \\
\hline 4 & $"$ & " & 3 & 3 & 6 \\
\hline 5 & $"$ & $"$ & 7 & - & $\tau$ \\
\hline 6 & $"$ & , & 5 & - & 5 \\
\hline 7 & $" 7$ & ", & 5 & - & 5. \\
\hline 8 & " 8 & " & 2 & - & 2 \\
\hline 9 & $" 9$ & ", & - & - & - \\
\hline 10 & " 10 & $"$ & 1 & - & 1 \\
\hline- & \multicolumn{2}{|c|}{-} & 40 & 8 & 48 \\
\hline
\end{tabular}

The following table shows the cause of death in the eight fatal cases.

TABLE II.-Eight Fatal Case of Empyema.

\begin{tabular}{|c|c|c|c|}
\hline No. & Age. & Complaint.; & Remarks. \\
\hline 1 & $2^{3^{6}}$ & Double empyerna. & $\begin{array}{l}\text { The left side opened, and the tight } \\
\text { side was aspirated three days before } \\
\text { death. At the necropsy pus was } \\
\text { found on the right side. }\end{array}$ \\
\hline 2 & $1_{\mathrm{f}}^{a^{2}}$ & Left empyema. & m. diphtheria \\
\hline 3 & $21^{3}$ & Left empyema. & $\begin{array}{l}\text { The empyema was nearly bealed } \\
\text { Peritonitis was the cause of death }\end{array}$ \\
\hline 4 & 2 & Empyema. & $\begin{array}{l}\text { hours after admission. } \\
\text { Died from diphtheria. Necropsg }\end{array}$ \\
\hline 5 & 3 & Left empyema. & 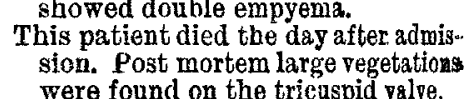 \\
\hline 6 & $1_{18}^{2}$ & Double empyema. & Operation was performed on the right \\
\hline $\begin{array}{l}7 \\
8\end{array}$ & $\begin{array}{l}3 \\
3 \frac{1}{2}\end{array}$ & $\begin{array}{l}\text { Left empyema. } \\
\text { Pyo-pericarditis. }\end{array}$ & $\begin{array}{l}\text { Death from pyæmia. } \\
\text { At the necropsy localised left om } \\
\text { pyetna was revealed. }\end{array}$ \\
\hline
\end{tabular}

A post-mortem examination was made in all the cases except No. T.

It will be seen that 3 of the above deaths occurred from causes quite independent of the empyema; therefore, deducting these from the whole number, there remain 45 cases, out of which number 5 died, giving a mortality of 11 per cent. Taking the cases under three years of age, 17 recovered and 5 died; bat of these 5 , it will be seen on reference to Table II., 2 died from diphtheria and one from peritonitis. Thus, out of 19 cases under three years of age, 17 recovered and 2 died, giving a mortality of 12 per cent Of the total number of cases, 25 were on the left side, 15 on the right, and 8 were double.

Table III._Cases of Double Empyema.

\begin{tabular}{|c|c|c|c|c|c|}
\hline No. & \multicolumn{2}{|c|}{ Age. } & $\begin{array}{l}\text { Number of } \\
\text { patients. }\end{array}$ & Recoveries. & Deaths. \\
\hline 1 & \multicolumn{2}{|c|}{ Under 2 years. } & 3 & 1 & $\mathbf{2}$ \\
\hline 2 & , 3 & ", & 2 & 1 & $1^{*}$ \\
\hline 3 & " 4 & " & - & $\therefore$ & $\ldots$ \\
\hline 4 & " 6 & , & 2 & 2 & - \\
\hline 5 & , 6 & " & - & - & - \\
\hline 6 & 197 & $"$ & 1 & 1 & - \\
\hline - & - & & 8 & 5 & 3 \\
\hline
\end{tabular}

* Died from diphtheria.

Deducting one case which died from diphtheria, there remain 7 cases and 2 deaths, giving a mortality of 285 per cent

With regard to a few other points of interest, further resection was required in 5 cases. Two of the empyemata had pointed before admission-one just ontside the left nipple, the other over the second and third ribs anteriorly, on the right side. Both were opened in the usual situation-viz., the eighth rib posteriorly. The eighth rib was most commonly removed, and occasionally the seventh or 